\title{
A GRADUATE COURSE IN FIRE PROTECTIVE DESIGN AND BUILDING CODES AN INDUSTRY AND UNIVERSITY COLLABORATION
}

\author{
M. J. Frye, P. Eng. Ph. D. ${ }^{(1)}$ and P. Zurkan ${ }^{(2)}$ \\ (1) Department of Civil Engineering, University of Manitoba \\ (2) Manager, Learning and Development, Winnipeg Construction Association \\ M.Frye@umanitoba.ca
}

\begin{abstract}
Since the fall of 2013, the Faculty of Engineering has offered a graduate course in Fire Protective Design and Building Codes based on Part 3 of the National Building Code of Canada. The course is made available to graduate students in architecture and to all branches of engineering. It is also offered to off campus practicing architects and engineers who wish to either take the course for credit or who would like to audit the course.

Introduction of this course into the graduate studies program at the University of Manitoba was the direct result of collaboration between the university Centre for Engineering Professional Practice and Engineering Education and industry. Industry financial support for the course instructors was provided by the Winnipeg Construction Association and the Association of Professional Engineers and Geoscientists of Manitoba. (Engineers Geoscientists Manitoba).

This paper provides an overview of the course objectives, the course content and the expected and realized outcomes. The course proved to be very popular, with course registration averaging between fourteen and eighteen graduate students each year. It was highly rated by the year end student course evaluations. It was particularly popular with international graduate students, many who came from countries where exposure to fire protective design and building codes was limited or non-existent. As a spin off from the course, in 2015, the Winnipeg Construction Association began offering a workshop/seminar series of five half day courses. These workshop/seminars have been oversubscribed and are attended by a very diverse group of construction practitioners that includes architects, engineers, building officials and contractors.
\end{abstract}

Keywords: collaboration, industry, fire protective design, codes.

\section{INTRODUCTION}

In 1981, a serious high-rise fire in Toronto resulted in a public inquiry [1] into highrise fire safety headed by the Honorable Judge John B. Webber. One of the recommendations contained in the inquiry report by Judge Webber dealt with university level education in fire protection provided to engineers and architects during their formal training.

"Examination of the weaknesses in the fire loss control systems in Canada makes it obvious that the main weakness results from problems in education, or lack of it.

The Association of Professional Engineers of Ontario and the Ontario Association of Architects should encourage universities to establish fire protection courses at the university level; and such courses should deal with both technical and social aspects of building design.

....the Office of the Fire Marshall with which they must deal, agreed that there is a need to improve the type of fire safety education that architects and engineers receive during their formal training."

While Judge Webber's recommendations concerning education in fire protective design were directed at the Ontario professional organizations, there was little argument that these recommendations applied to design professionals throughout Canada.

In Manitoba, until 1985 there was little available in terms of formal training in fire protective design and building codes for students in both architecture and engineering. At this time, representatives of the City of Winnipeg developed a three day course in Fire Protective Design and Building Codes that was offered to practicing engineers and architects through the Department of Continuing Education of the University of Manitoba. 
This three day course was extremely popular with architects and engineers, many who expressed the wish that a similar course had been offered in their undergraduate programs. The course was offered each year for four years. From that time on, and until recently, instruction within the University of Manitoba engineering and architecture programs was limited primarily to invited one or two hour lectures by City of Winnipeg building department officials. Engineers and architects entering the workforce were essentially left to rely on on-the-job training to acquire proficiency in the application of the fire protection requirements of the building code to their projects.

In the fall semester of 2013, CIVL 7350 FIRE PROTECTIVE DESIGN \& BUILDING CODES was introduced as a pilot course into the graduate studies program at the University of Manitoba. As a result of collaboration with the Engineers Geoscientists Manitoba (EGM) and the Winnipeg Construction Association (WCA), the course has been offered each fall semester and will again be offered in 2016 .

\section{CIVL 7350 FIRE PROTECTIVE DESIGN \& BUILDING CODES}

CIVL 7350 is a graduate level course offered by the Department of Civil Engineering at the University of Manitoba. The seed funding was provided by the Chair in Design Engineering.

After a successful first year, the Winnipeg Construction Association (WCA) and the Association of Professional Engineers of Manitoba (APEGM) were approached to jointly fund the course for the fall semester of 2014 which they both agreed to do. Also, at that time, an arrangement was also made with the WCA to provide a series of workshop/seminars that could be made available to both members and non-members of the WCA that included a broad range of construction practitioners.

\subsection{Course Objectives}

The introduction of the course into the graduate studies program had two main objectives:

1. To provide graduate students in engineering and architecture wishing to pursue a career in the design and construction of commercial buildings with a working knowledge of Part 3 Fire Protection, Occupant Safety and Accessibility of the National Building Code of Canada (NBCC) [2].
2. To involve the professional associations, the Winnipeg Construction Association in a collaborative effort to ensure that the course continues to be offered on a yearly basis within the graduate studies program.

A working knowledge of Part 3 of the NBCC means the achievement of an understanding of the relevant defined terms used throughout the NBCC, an understanding of the fundamental principles of fire protective design as they apply to buildings and an understanding of the process used to carry out a Part 3 Code Analysis for a given commercial building design project.

If the levels of Part 3 code expertise can be described as Novice, Intermediate and Expert as represented in Figure 1, the time necessary to go from a Novice Level to an Intermediate Level can be lengthy if knowledge is obtained only through on-the-job training and/or experience. It is the goal of ENG 7350 that successful completion of the course places a student well within the range of the Intermediate Level of Part 3 code expertise.

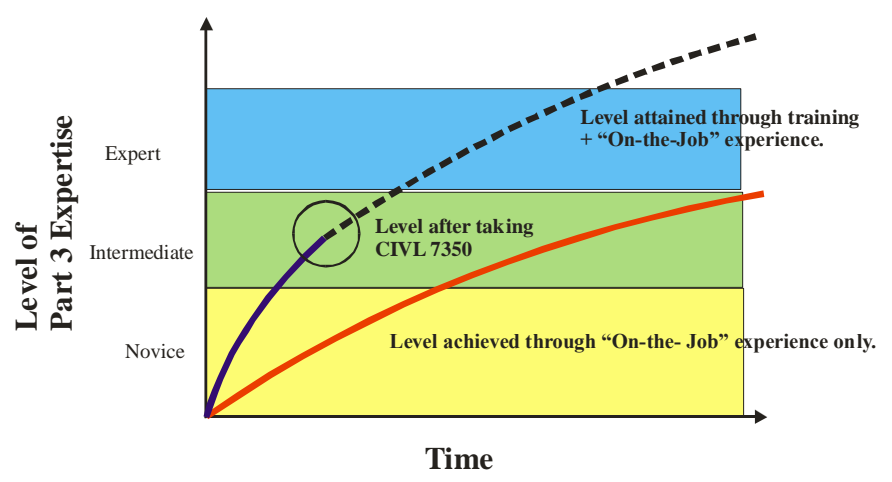

Figure 1 - Part 3 Code Expertise.

\section{COURSE CONTENT AND STUDENT EVALUATION}

The course content is based on Part 3, Fire Protection, Occupant Safety and Accessibility of the 2010 NBCC and is delivered over the thirteen week fall semester. Fire protection principles and applicable code requirements are presented in the structured order that an experienced plan examiner would carry out a plan review and code analysis of a building design to determine Part 3 code compliance.

The fire protection topics covered include; construction types, compartmentation, fire resistance rating, flame-spread rating, spatial separation, means of 
egress, fire suppression, fire alarm and detection systems and special topics. Case histories are introduced throughout the lectures to demonstrate the fire protection principle that a specific code requirement is intended to address.

Students are evaluated on the basis of two takehome term assignments and a take home final exam. Out of necessity these assignments are open book (Part 3 of the NBCC). The two term tests and final exams cover all of the topics covered in the lectures. The assignments and final take-home exam were quite long so students were given a week to complete. The problems proposed were all prepared by senior plan examiners at the City of Winnipeg and reflected fire protection design problems frequently encountered in the plan review and approval process.

\section{EXPECTED OUTCOMES AND REALIZED OUTCOMES}

- When CIVL 7350 was first offered in 2013 it was expected that participants who successfully completed the course would have achieved a working knowledge of Part 3. This would be primarily be measured by the grades achieved in the two assignments and final exam. There is strong evidence that this outcome has been realized.

Over the three years that the course has been offered all participants ranked extremely well indicating that they understood the principles of fire protection and the structured application of Part 3 in the fire protection analysis process.

- It was expected that practising engineers and architects who attended and successfully completed the course would in turn be able to develop or strengthen their inhouse capability to carry out a Part 3 code analysis. There would be less reliance on outside "code consultants" to deal with the Part 3 fire protection code analysis.

Measurement of this expected outcome is more difficult and will need to be assessed over time. However, there is some early evidence that consulting firms are heading in this direction. At least three of the companies that had a member of their organization attend the first course have had other members of their company attend subsequent courses. There is at least one instance where a course participant questioned an aspect of a design that saved thousands of dollars in unnecessary construction costs.
- It was expected that the collaboration with the professional associations and the WCA would be a "Win-Win" arrangement that could lead to more involvement in Part 3 code education outside of the university.

In 2014, the Learning and Development Division of the WCA working with the instructors of CIVL 7350 introduced a Workshop/Seminar Series of four half day modules on specific Part 3 Code topics. These courses, administered by the WCA, proved to be extremely popular among all of the construction community with many of the companies sending more than one of their designers to the courses.

Feedback obtained through the course evaluations was extremely positive and there were requests for additional topic modules. The WCA Workshop/Seminar Series was increased to five modules and was again offered on 2015. Registration for each of the modules was capped at the seminar room capacity.

The Workshop/Seminar Series will be again offered in 2016. The Building Owners and Managers Association of Manitoba (BOMA) is interested in the WCA offering a course in Part 3 tailored to their needs.

- Each year, CIVL 7350 has been attended by a significant number of international students most of whom previously had little awareness of or exposure to the principles of fire protective design. It was expected that for those of these students who did return to their homelands, the exposure to fire protective design would apply to their designs

The following are just a few of the comments received from international students following completion of the course.

...I can truly say that I have learned the interesting and informative information that I did not know before. ...After my graduation and when I will come back home, I will try to include this new extremely useful design technique in our work environment for life safety and time and money saving for a structural project.

...A graduate course such as Fire Protective Design and Building Codes which is based on Part 3 of the National Building Code of Canada is strongly helps to understand the essentials behind the code, the regulatory and code development processes."

\section{CONCLUSIONS}


The effectiveness of attending a structured course to acquire a working knowledge of fire protective design has been proven. Such a course offered at the university level so that graduates entering the workforce start with a working knowledge of fire protective design and do not have to rely entirely on on-the job training. In addition, the need for continuing education in Part 3 by means of seminars and workshops for all construction practitioners is evident.

\section{References}

[1] Report of the Public Inquiry into Fire Safety in Highrise Buildings, Volumes 1 and 2. The Honorable Judge John B. Weber Judge of the County Court of the County of Dufferin, December 1983.

[2] 2010 National Building Code of Canada, Canadian Commission on Building and Fire Codes, National Research Council of Canada, Ottawa. 